\title{
The Respirative Breakdown of Glucose by Saccharomyces cerevisiae: an Assessment of a Physiological State
}

\author{
By OTHMAR K ̈̈PPELI, * MONICA ARREGUIN AND MARTIN RIEGER \\ Department of Biotechnology, Swiss Federal Institute of Technology, Hönggerberg, \\ 8093 Zürich, Switzerland
}

(Received 21 September 1984; revised 16 November 1984)

Cells of Saccharomyces cerevisiae exhibiting respirative glucose metabolism in continuous culture were able to use ethanol as a co-substrate. The ethanol uptake rate was dependent on the residual respirative capacity of the cells. The activities of gluconeogenic enzymes and of malate dehydrogenase were higher in cells degrading glucose respiratively than in cells metabolizing glucose respiro-fermentatively, but were lower than in cells growing on ethanol only. The pattern of distribution of the mitochondrial cytochromes was similar but the differences were less distinct. In synchronously growing cells, the activities of gluconeogenic enzymes and of malate dehydrogenase oscillated, with activities increasing during the budding phase. The increase was preceded by the appearance of ethanol in the culture medium.

\section{INTRODUCTION}

The growth of Saccharomyces cerevisiae in batch culture with glucose as the carbon source is characterized by two growth phases. In the first growth phase glucose is utilized with the concomitant production of ethanol, which is subsequently oxidized in the second growth phase (Fiechter et al., 1981). This growth behaviour was explained at the molecular level by a repression/derepression mechanism of respirative pathways, since in the presence of glucose major differences in the activities of enzymes of the tricarboxylic acid cycle (Polakis et al., 1965), and the glyoxylate shunt (Barnett \& Kornberg, 1960) have been observed. When glucose served as carbon source for the cells, additional enzyme systems were found to be repressed, including gluconeogenic enzymes (Gancedo et al., 1965; Witt et al., 1966; Gancedo \& Schwerzmann, 1976), $\alpha$-glucosidases (Wijk et al., 1969), and invertase ( $\beta$-fructofuranosidase) (Gascon et al., 1968 ). By analogy with a comparable phenomenon in bacteria the term catabolite repression (glucose repression), introduced by Magasanik (1961), was used to describe the effect of glucose in yeasts, although the mechanism is generally assumed to be different from the cyclic AMPmediated process in Escherichia coli (de Crombrugghe \& Pastan, 1978).

Continuous culture studies with $S$. cerevisiae have shown that the respirative breakdown of glucose is possible at low dilution rates in a glucose-limited chemostat (Beck \& von Meyenburg, 1968). The activities of several enzymes changed depending on the metabolic conditions.

More recent continuous culture studies (Rieger et al., 1983; Petrik et al., 1983), have suggested that the regulation of glucose metabolism in yeasts of the genus Saccharomyces is based on the limited respirative capacity of the cells. Up to a certain dilution rate, oxygen uptake rate was linearly related to the growth rate of both $S$. cerevisiae and $S$. uvarum (Rieger et al., 1983; Petrik et al., 1983) and glucose was degraded respiratively (respirative glucose metabolism). At a species specific dilution rate, oxygen uptake levelled off and a branched glucose metabolism with ethanol formation occurred (respiro-fermentative glucose metabolism). Pure glycolytic

Abbreviations: PEPCK, phosphoenolpyruvate carboxykinase; FBPase, fructose-1,6-diphosphatase; MDH, malate dehydrogenase. 
glucose breakdown with ethanol as the end product of energy metabolism occurred under anaerobic conditions only (fermentative glucose metabolism).

In this paper we report on the co-utilization of glucose and ethanol by $S$. cerevisiae in continuous culture. Mitochondrial cytochromes were assayed, together with three enzymes PEPCK, FBPase and MDH - that are strongly repressed by glucose in batch culture. The results obtained from $S$. cerevisiae degrading glucose respiro-fermentatively were compared with those obtained from $S$. cerevisiae metabolizing glucose entirely respiratively, or growing on ethanol only.

\section{METHODS}

Cultivation conditions. S. cerevisiae H1022 (ATCC 32167) was used in all experiments. Since respirative glucose metabolism can be achieved only in continuous culture all experiments were done in a chemostat. The growth conditions and equipment were identical to those used by Rieger et al. (1983). The dilution rates used are indicated in the legends of the table and the figures. The medium contained either $3 \%(\mathrm{w} / \mathrm{v})$ glucose or $2 \cdot 3 \%(\mathrm{w} / \mathrm{v})$ ethanol as carbon source: the lower concentration of ethanol compensates for the higher carbon content of ethanol as compared with glucose.

Pulse experiments. The co-substrate ethanol was added with a syringe to continuously growing cells with glucose as carbon source. During the experiment the cells used both glucose and ethanol simultaneously, since medium feed was not interrupted. The final concentration of ethanol was $3 \mathrm{~g} \mathrm{l}^{-1}$. It follows that a theoretical biomass increase of $2.2 \mathrm{~g}^{-1}$ could occur $\left[Y_{\mathrm{x} / \mathrm{FtOH}} 0.72 \mathrm{~g}\right.$ dry cell weight ( $\mathrm{g}$ ethanol) $\left.{ }^{-1}\right]$. Because the medium supply was continuous an actual biomass increase of $<1.5 \mathrm{~g} \mathrm{l}^{-1}$ occurred, which is $<10 \%$ of the biomass resulting from the utilization of glucose $\left(15 \mathrm{~g}^{-1}\right)$.

The ethanol uptake rate $\left(q_{\mathrm{E} t \mathrm{OH}}\right)$ was calculated as follows:

$$
q_{\mathrm{E}: \mathrm{OOH}}=1 / x(\mathrm{~d}[\text { Ethanol }] / \mathrm{d} t-D[\text { Ethanol }])
$$

$\mathrm{d}[$ Ethanol] $/ \mathrm{d} t$ was determined graphically as the slope of the ethanol concentration curve (graphic regression).

Preparation of cell extracts. Cells (3-5 g wet weight) collected from the bioreactor were centrifuged and washed with $50 \mathrm{~mm}$-phosphate buffer, $\mathrm{pH} 7.5$. The pellet was resuspended in the same buffer together with glass beads $(0.02-0.05 \mathrm{~mm}$ in diameter). The mixture was ground for $40-50 \mathrm{~s}$ using a handmixer equipped with a notched disk. The glass beads were removed by filtration through a sintered glass frit. From the filtrate, cells and cell debris were removed by centrifugation at $15000 \mathrm{~g}$ for $10 \mathrm{~min}$. All manipulations were carried out at $4{ }^{\circ} \mathrm{C}$.

Measurement of cytochrome contents and enzyme activities. Cytochrome contents were calculated according to Petrik et al. (1983) from the reduced minus oxidized difference spectrum of whole cells.

PEPCK was measured according to Hansen et al. (1976). For FBPase the assay of Gancedo \& Gancedo (1971) was used. MDH activity was analysed according to Flury et al. (1974). Specific activites of the PEPCK and the FBPase are expressed as nmol substrate converted $\min ^{-1}(\mathrm{mg} \text { protein })^{-1}$, that of $\mathrm{MDH}$ as $\mu$ mol substrate converted $\min ^{-1}$ (mg protein) $)^{-1}$.

Protein was measured with a Bio-Rad protein assay kit, with bovine serum albumin as a protein standard.

Product analyses. Ethanol in the culture liquid was analysed according to Rieger et al. (1983). The carbon dioxide and oxygen concentration of the exit gas was monitored using a gas analyser (Bioengineering AG, Wald, Switzerland). Oxygen uptake and carbon dioxide production rates were calculated according to Gmünder $e t a l$. (1981).

\section{RESULTS}

From continuous culture experiments it became obvious that $S$. cerevisiae has a branched pathway for glucose breakdown (Rieger et al., 1983). At low glucose feed rates in continuous culture, glucose was metabolized purely respiratively. At high feed rates, ethanol was produced by the cells. The breakdown of glucose was respiro-fermentative. It was hypothesized that the type of glucose metabolism is governed by the respiratory capacity of the cells (Rieger et al., 1983). In order to substantiate this hypothesis ethanol, a substrate that can only be metabolized respiratively, was added to a culture of $S$. cerevisiae which was degrading glucose respiratively (Fig. 1). The addition was made at different dilution rates, i.e. at different remaining respirative capacities of the cells. From the decrease with time of ethanol concentration in the culture medium, ethanol uptake rates $\left(q_{\mathrm{EtOH}}\right)$ were calculated taking into account the amount of ethanol being washed out by the continuous medium flow. The experiments showed the following. (1) Ethanol was used by cells immediately as a co-substrate. (2) There was a clear dependence of the 

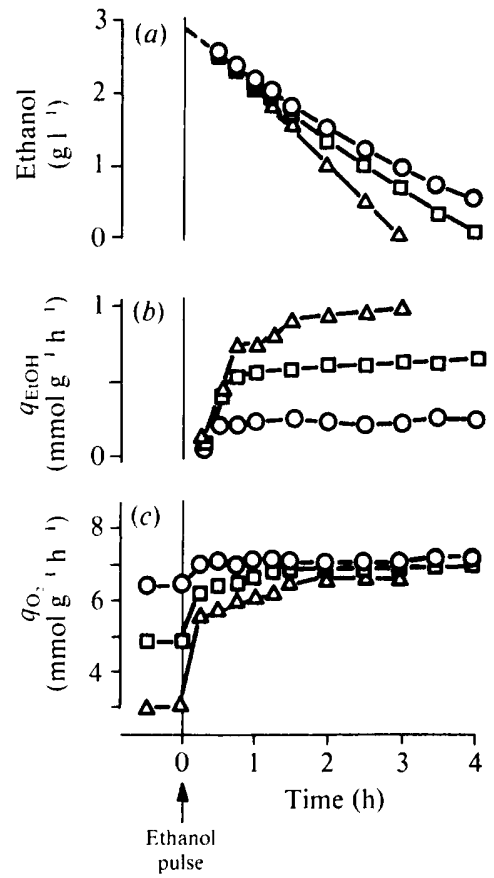

Fig. 1. Ethanol pulse to cells of $S$. cerevisiae respiratively degrading glucose at different dilution rates $\left(\triangle, D=0.10 \mathrm{~h}^{-1} ; \square, D=0.20 \mathrm{~h}^{-1} ; O, D=0.25 \mathrm{~h}^{-1}\right)$ in a continuous culture. (a) Ethanol concentration; $(b)$ specific ethanol uptake rates; $(c)$ specific oxygen uptake rates.

ethanol uptake rate on the residual respirative capacity: the higher the residual respirative capacity, the higher the ethanol consumption rate of the cells. (3) The final oxygen uptake rate of the cells was independent of the dilution rate at which the ethanol was added (Fig. 1). It reached $7-7.5 \mathrm{mmol} \mathrm{g} \mathrm{g}^{-1} \mathrm{~h}^{-1}$, which was only slightly below the maximum of $8 \mathrm{mmol} \mathrm{g}^{-1} \mathrm{~h}^{-1}$ obtained in a glucose chemostat (Rieger et al., 1983). No appreciable acetate formation was observed after the ethanol pulse, which contrasts with the acetate formation observed after giving a pulse of glucose to respiratively growing cells (Petrik et al., 1983).

Because these results and results from mixed substrate cultivations (Rieger et al., 1983) show that ethanol is assimilated by cells respiratively degrading glucose, the question arose as to the regulation of gluconeogenic enzymes, since they are supposed to be repressed when glucose serves as the substrate. Therefore, the activities of key enzymes of gluconeogenesis were determined together with the mitochondrial cytochrome contents of cells of $S$. cerevisiae respiratively degrading glucose, and were compared with those of cells grown under other physiological conditions.

\section{Asynchronously' growing cells}

The mitochondrial cytochrome content of cells of $S$. cerevisiae was higher, on average, in cells degrading glucose respiratively than in those metabolizing glucose respiro-fermentatively (Table 1). The differences in cytochrome contents were greater when cells of higher respirative growth rates were used (e.g. $D=0 \cdot 20 \mathrm{~h}^{-1}$ ) because steady-state cytochrome contents of the cells are dependent on the growth rate, as shown for $S$. utarum by Petrik et al. (1983). The cytochrome content of cells metabolizing glucose respiratively was only slightly lower than that of ethanolassimilating cells growing at the same dilution rate (Table 1).

The activities of two key enzymes of gluconeogenesis, PEPCK and FBPase, were highest in cells grown on ethanol and lowest in cells degrading glucose respiro-fermentatively. Cells with respirative glucose metabolism had activities between the two extremes (Table 1). Similar 
Table 1. Comparison of mitochondrial cytochrome contents, FBPase, PEPCK and MDH activities in cells of $S$. cerevisiae

The yeast was metabolizing glucose respiratively $\left(D=0.10 \mathrm{~h}^{-1}\right)$ or respiro-fermentatively $(D=$ $\left.0.35 \mathrm{~h}^{-1}\right)$, or growing on ethanol $\left(D=0.10 \mathrm{~h}^{-1}\right)$. Cytochrome contents are given in pmol (mg cell dry wt $)^{-1}$, and enzyme activities in nmol substrate converted (mg protein $)^{-1} \min ^{-1}$. All values represent means $\pm \mathrm{SD}, n=5$ sets.

$\begin{array}{lcccccc} & \text { Cyt. } a & \text { Cyt. } b & \text { Cyt. } c & \text { FBPase } & \text { PEPCK } & \text { MDH } \\ \begin{array}{l}\text { Glucose } \\ \left(D=0 \cdot 10 \mathrm{~h}^{-1}\right)\end{array} & 45 \pm 4 & 41 \pm 2 & 119 \pm 4 & 6.5 \pm 1 \cdot 0 & 18 \cdot 5 \pm 2 \cdot 0 & 2700 \pm 90 \\ \begin{array}{l}\text { Glucose } \\ \left(D=0.35 \mathrm{~h}^{-1}\right)\end{array} & 24 \pm 4 & 45 \pm 5 & 97 \pm 7 & 3 \cdot 6 \pm 0 \cdot 6 & 6 \cdot 4 \pm 1 \cdot 9 & 740 \pm 10 \\ \begin{array}{c}\text { Ethanol } \\ \left(D=0.10 \mathrm{~h}^{-1}\right)\end{array} & 46 \pm 1 & 56 \pm 3 & 143 \pm 6 & 10 \cdot 1 \pm 0 \cdot 4 & 672 \pm 52 & 16610 \pm 880\end{array}$

results were obtained for $\mathrm{MDH}$, an enzyme that takes part in several metabolic pathways and is strongly repressed by glucose (Haegele et al., 1978).

\section{Synchronously growing cells}

The strain of $S$. cerevisiae used in this study had a tendency for self-synchronization when glucose was metabolized respiratively. Therefore, all enzyme activities and cytochrome contents were recorded during a division cycle.

Oxygen uptake rate and carbon dioxide production rate showed the typical pattern of a synchronized culture (Fig. 2) established by von Meyenburg (1969). It is noteworthy that in each cycle ethanol was produced by the cells (Fig. 2) at the beginning of the cell division cycle, although oxygen partial pressure was never below $60 \%$ of air saturation; this coincided with the mobilization of internal carbohydrate reserve material (Küenzi \& Fiechter, 1969).

The content of mitochondrial cytochromes did not change significantly during the cell cycle of the synchronously growing culture. However, the three enzymes assayed exhibited considerable changes of activity in the course of the division cycle (Fig. 3). For all three enzymes, activities increased as the reproducing phase started and decreased when the cells entered the resting phase of the cell cycle. The activity determined in asynchronously growing cells represented an average value of the peak activities (Fig. 3), which indicates that a synchronous culture yields a more differentiated picture of enzyme regulation in cells than does an asynchronous culture.

\section{DISCUSSION}

Respirative glucose metabolism by Saccharomyces-type yeasts can only be obtained by controlling the glucose feed rate in a continuous cultivation system. By thus providing a number of unique and controllable steady-state environments many questions concerning metabolic regulation have been answered. In a series of continuous culture experiments Rieger et al. (1983) established a limited respiratory capacity as the basis for the branched pathway of glucose breakdown exhibited by $S$. cerevisiae at high dilution rates in continuous culture. The results of ethanol pulse experiments reported here (Fig. 1) support this concept. Pulsing ethanol to a glucose-utilizing culture growing at a low dilution rate yielded higher ethanol uptake rates than did pulsing ethanol to faster growing cells. The rate of ethanol uptake by cells respiratively degrading glucose was limited by the residual respiratory capacity of the cells. Respiratory capacity represents a bottleneck for respirative substrate utilization. The more respirative capacity is occupied by glucose the lower ethanol uptake rates become, as the pulse experiments indicated.

Cells degrading glucose respiratively had lower cytochrome contents and markedly lower activities of the gluconeogenic enzymes PEPCK and FBPase than did ethanol-grown cells. However, the cytochrome contents and enzyme activities of the former were significantly higher than in cells with respiro-fermentative glucose metabolism (Table 1) or as was reported for 


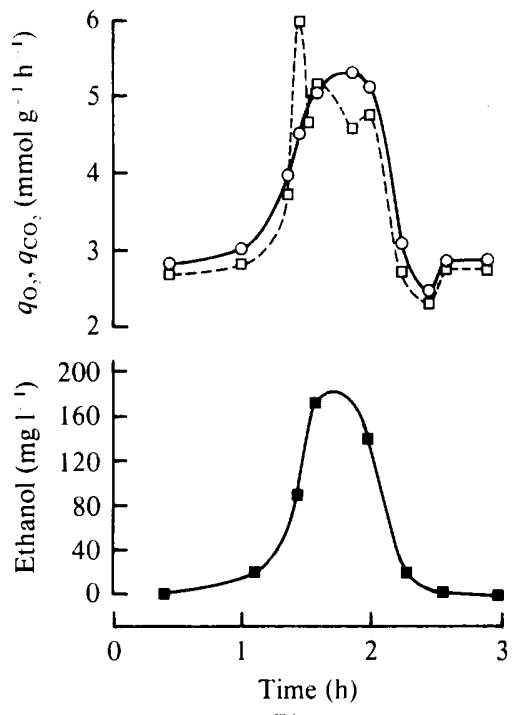

Fig. 2
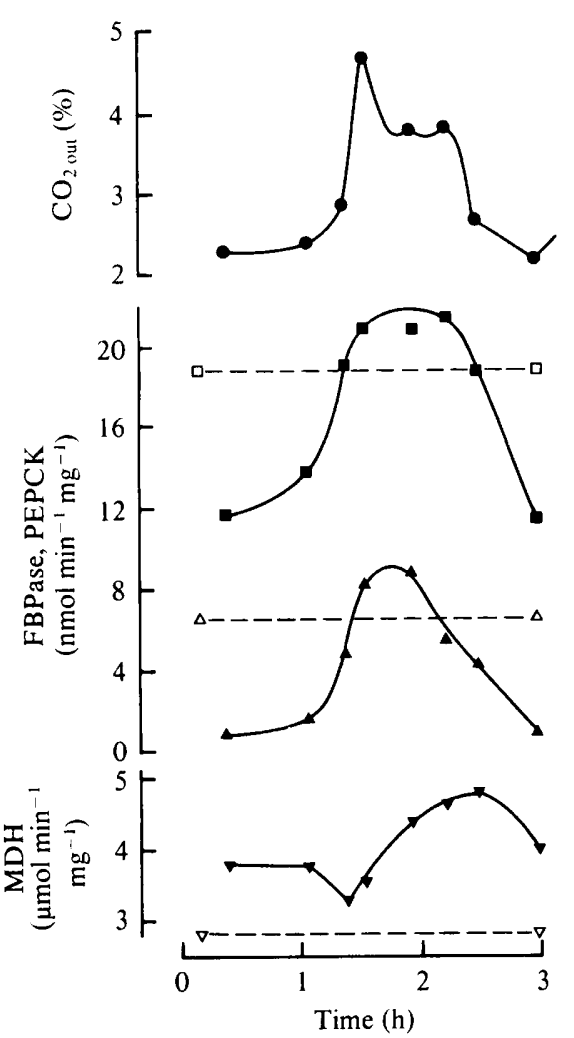

Fig. 3

Fig. 2. Rates of oxygen uptake $(O)$ and carbon dioxide production $(\square)$ of a synchronously growing culture of $S$. cerevisiae. $\square$, Ethanol concentration in the culture liquid of synchronously growing yeast exhibiting respirative glucose metabolism $\left(D=0 \cdot 15 \mathrm{~h}^{-1}\right)$.

Fig. 3. Activities of gluconeogenic enzymes and malate dehydrogenase during the cell cycle of $S$. cerevisiae., $\mathrm{CO}_{2}$ evolution indicating synchronous growth of the culture $\left(D=0.15 \mathrm{~h}^{-1}\right) ; \square, \mathrm{PEPCK}$; $\Delta$, FBPase; $\nabla, M D H$. The dashed lines with the open symbols indicate the corresponding activities in an asynchronously growing culture with a dilution rate of $0 \cdot 10 \mathrm{~h}^{-1}$.

batch-grown cells (Gancedo \& Schwerzmann, 1976) and may well account for the immediate utilization of the co-substrate ethanol. It seems that the degree of enzyme expression is not only the result of the presence or absence of an effector but also depends on metabolic rates. Beck \& von Meyenburg (1968) made similar observations for enzymes of the tricarboxylic acid cycle and the glyoxylate bypass. In any case, seemingly unnecessary enzymes are expressed under particular conditions in continuous culture, which means that in this cultivation system gene expression is more universal than in batch culture. Therefore, in continuous culture properties are expressed that are never manifest in batch cultures or appear only transiently. Microbial gene expression seems to be influenced by cultivation conditions, which is an important observation in view of biotechnological applications of microbial systems.

The oscillation of enzyme activities in the synchronous culture probably results from the short-term ethanol production by the cells at the beginning of the budding phase. In asynchronously growing cells, ethanol concentration in the culture liquid remains below the detection limit of approximately $5 \mathrm{mg}^{-1}$. Nevertheless, during the cell cycle of an individual cell, ethanol is produced, but is then taken up by adjacent cells which are in other phases of the cell cycle.

Synchronization of cells degrading glucose respiratively was described by von Meyenburg (1969) and seemed to be induced by dilution rate shifts. In our experience spontaneous synchronization occurs mainly when the continuous culture is started after a batch culture. 
Although the reason for spontaneous synchronization is not known, the particular metabolism of Saccharomyces-type yeasts seems to be the basis. We have regularly observed synchronization with yeasts of this genus when glucose was degraded respiratively $(O$. Käppeli, unpublished data). The production of ethanol during the cell cycle may represent the signal for synchronization. This is supported by the fact that synchronization is easily obtained and maintained in a well-mixed bioreactor (Meyer \& Beyeler, 1984). Furthermore, synchronization could be prevented by lowering the stirring intensity of the bioreactor used in this study. The dependence of synchronization on the homogeneity of the reactor content indicates that an extracellular component could be responsible for the triggering of synchronous growth.

This work was supported by the Swiss National Foundation, grants nos 3.465-0.79 and 3.281-0.82.

\section{REFERENCES}

Barnett, J. A. \& Kornberg, H. L. (1960). The utilization by yeast of acids of the tricarboxylic acid cycle. Journal of General Microbiology 23, 65-82.

BeCK, CH. \& von MeyenburG, H. K. (1968). Enzyme pattern and aerobic growth of Saccharomyces cerevisiae under various degrees of glucose limitation. Journal of Bacteriology 96, 479-486.

de Crombrugghe, B. \& Pastan, I. (1978). Cyclic AMP, the cyclic AMP receptor protein and their dual control of the galactose operon. In The Operon, pp. 303-324. Edited by J. H. Miller \& W. S. Reznikoff. Cold Spring Harbor, New York: Cold Spring Harbor Laboratory.

Fiechter, A., Fuhrmann, G. F. \& KäPPELI, O. (1981). Regulation of glucose metabolism in growing yeast cells. Advances in Microbial Physiology 22, 123-183.

Flury, U., Heer, B. \& Fiechter, A. (1974). Isoenzyme pattern of malate dehydrogenase during respiratory derepression in Schizosaccharomyces pombe. Archives of Microbiology 97, 141-148.

GANCEDO, J. M. \& GANCEDO, C. (1971). Fructose-1,6diphosphatase, phosphofructokinase and glucose-6phosphate dehydrogenase from fermenting and nonfermenting yeasts. Archives of Microbiology 76, 132138.

GanCEDo, C. \& SChWERzmanN, N. (1976). Inactivation by glucose of phosphoenolpyruvate carboxykinase from Saccharomyces cerevisiae. Archives of Microbiology 109, 221-225.

Gancedo, C., Salas, M. L., Giner, A. \& Sols, A. (1965). Reciprocal effects of carbon sources on the level of an AMP-sensitive fructose-1,6-biphosphatase and phosphofructokinase in yeast. Biochemical and Biophysical Research Communications 20, $15-20$.

Gascon, C., Neumann, N. P. \& Lampen, J. O. (1968). Comparative study of the properties of the purified internal and external invertases from yeast. Journal of Biological Chemistry 243, 1573-1577.

GMÜNDER, F. K., KÄPPELI, O. \& FiechTER, A. (1981). Chemostat studies on the hexadecane assimilation by the yeast Candida tropicalis. I. Influence of the dilution rate and specific growth limitations on the basic culture parameters. European Journal of Applied Microbiology and Biotechnology 12, 129-134.
Haegele, E., NeefF, J. \& Mecke, D. (1978). The malate dehydrogenase isoenzymes of Saccharomyces cerevisiae. Purification, characterisation and studies on their regulation. European Journal of Biochemistry 83, 67-76.

Hansen, R. J., Hinze, H. \& Holzer, H. (1976). Assay of phosphoenolpyruvate carboxykinase in crude yeast extracts. Analytical Biochemistry 74, 576-584.

KüEnzi, M. T. \& FIEchteR, A. (1969). Change in carbohydrate composition and trehalase activity during the budding cycle of Saccharomyces cerevisiae. Archives of Microbiology 64, 396-407.

MaGasaniK, B. (1961). Catabolite repression. Cold Spring Harbor Symposia on Quantitative Biology 26, 249-256.

von Meyenburg, H. K. (1969). Energetics of the budding cycle of Saccharomyces cerevisiae during glucose limited aerobic growth. Archives of Microbiology 66, 289-303.

Meyer, C. \& Beyeler, W. (1984). Control strategies for continuous bioprocesses based on biological activities. Biotechnology and Bioengineering 26, 916925.

Petrik, M., Käppeli, O. \& Fiechter, A. (1983). An expanded concept for the glucose effect in the yeast Saccharomyces uvarum: involvement of short- and long-term regulation. Journal of General Microbiology 129, 43-49.

Polakis, E. S., Bartley, W. \& Meek, G. A. (1965). Changes in the activities of respiratory enzymes during the aerobic growth on different carbon sources. Biochemical Journal 97, 298-302.

Rieger, M., KäPPELI, O. \& Fiechter, A. (1983). The role of a limited respiration in the incomplete oxidation of glucose by Saccharomyces cerevisiae. Journal of General Microbiology 129, 653-661.

WIJK, R., OUWEHAND, J., BOS, T. \& VAN DEN KONINGSBERGER, V. V. (1969). Induction and catabolite repression of alpha-glucosidase synthesis in protoplasts of Saccharomyces carlsbergensis. Biochimica et biophysica acta 186, 178-191.

Witt, J., Kronau, R. \& Holzer, H. (1966). Isoenzyme der Malatdehydrogenase und ihre Regulation in Saccharomyces cerevisiae. Biochimica et biophysica acta 128, 63-73. 